\title{
Analysis of Pre-Existing Investment Behavior and Influence of Trading Apps
}

\author{
Anish Guddati ${ }^{1}$ and Dhruva Bhat ${ }^{\#}$ \\ 'St. Mark's School of Texas, Dallas, TX, USA \\ \#Advisor
}

ABSTRACT

The last few years have seen a rise in trading apps, and Robinhood is one trading app that has attracted millennials. This paper explores trading apps such as Robinhood and their role in providing financial inclusion and safe trading opportunities. This paper discusses investment behavior in the status quo, explaining overconfidence, sociability, and the disposition effect. Investment behavior can include the behavioral biases and common notions investors utilize for trading. Furthermore, this paper assesses the design and business model of Robinhood. Five expert investors were interviewed (such as a professor and other MBA graduates from Wharton School of Business, financial experts from private equity firms in the US and Mexico, and a JP Morgan investment banking professional), and five casual investors were interviewed to understand their opinions on investment behavior, certain trading apps, common criticisms of stock trading, and solutions to these concerns. The findings led to the conclusion that investment behavior is harmful in the status quo. Results did indicate that Robinhood does promote at least some dangerous behavior through excessive active trading and is one example of a problematic trading app through the 4th Industrial Revolution, but trading apps can only amplify behavioral biases most retail investors already display.

\section{Introduction}

Society is amidst a 4th Industrial Revolution bringing new biotechnology, physical innovations, and advances in digital technology. These technological innovations have fundamentally changed the finance industry in many ways, such as through the rise of mobile trading apps that allow people to invest directly in the stock market. These apps, such as Robinhood, hope to bridge economic inequality with increased functionality through mechanisms like commissionfree trading. They advertise lowered transaction costs and enable easy account creation, driving the new age of finance. The stated goal of these apps is to increase financial inclusion by encouraging and enabling more users (especially younger people) to participate in the stock market. Participation and inclusion entail the ability to succeed; participation set up for failure discourages users from investing.

However, recent controversies and scandals highlight the dark side of the digital transformation of finance. In early 2021, CBS News (2021) brought attention to the story of Alex Kearns, a Robinhood user and teenager who mistakenly thought he had lost $\$ 750,000$ on Robinhood. He attempted to contact customer service but only received automated responses. In his emotional distress, he took his own life. Even though this incident does not perfectly correlate with this paper's ideas on the designs and business models of trading apps, it sparked intense scrutiny of platforms such as Robinhood. This scrutiny accused these trading apps of targeting young investors like Alex and turning uninformed risk-taking into an addictive game. This paper analyzes trading apps like Robinhood and their role in financial inclusion. Other trading apps may apply to some of this paper's descriptions about Robinhood. Robinhood is a mere example of a problematic trading app. With that in mind, this paper analyzes typical investment behavior and how trading apps may amplify financial exclusion, which is the exclusion of financial services, and the ability to succeed. 
Investment behavior shows dangerous signs with excessive, risky, and uninformed trading. With apps like Robinhood, millennial investors believe they are capable of earning massive profits. CFA Institute (2021) indicates "meme stocks" have now surfaced through platforms like Reddit, and stock trading is influenced by social media comical chatter. Also, Sayan Chaudry and Chinmay Kulkarni (2021), academics affiliated with Carnegie Mellon University, show that investors are purposefully engaging with this comical game of "meme stocks." However, it is crucial to analyze investment behavior because while trading apps can encourage harmful habits, these habits emerge from flaws that retail investors may already have. Trading apps can amplify those flaws and feed into behavioral problems. In combination, trading apps and investment behavior can disrupt financial inclusion, a primary goal of trading apps and other technology with the rise of FinTech and the 4th Industrial Revolution.

This paper seeks to contribute to an emerging literature base on online trading platforms and their potential to increase access to the stock market. This paper uses interviews with experts and everyday users of trading apps to answer the research question: "How do the design choices and business models of trading apps affect the ability of everyday investors to successfully participate on the stock market?" The hypothesis based on existing research is that while trading apps increase access, they can draw in uninformed users and encourage risk-taking.

Literature exists on investment behavioral biases with Barber and Odean (2011), Fink (2021), Kannadhasan (2015), and more. Due to recent discussions over Robinhood, such as the GameStop crisis and the Alex Kearns incident, bountiful news articles have shown up to discuss our dangerous stock trading situation. Some studies talk about Robinhood like Welch (2020), Steib (2021), and Chaudry and Kulkarni (2021).

However, this paper is about the role of modern trading apps in financial inclusion and pre-existing investor behavior. Rather than merely highlighting past trading app scandals, this paper will discuss fairness for retail investors with these trading apps and if any action needs to be taken subsequently. Additionally, this paper examines the interconnectedness of pre-existing investment behavior, financial inclusion, and trading apps. This research methodology is unique in comparison to the existing literature. The findings in this paper are from interviewing a mix of highly qualified professionals and casual investors.

\section{Literature Review}

This literature review includes biases in investor behavior, financial inclusion and exclusion, and the designs and business models of trading apps. All three parts intertwine. Trading apps ultimately amplify typical investor behavior, so it is essential to understand behavior beforehand. Analyzing typical investment behavior is critical to understanding how trading apps change the status quo for retail investors, who are individual and non-professional stock traders. Financial inclusion is relevant to understand the role of trading apps in society and their significance with increased access and chances for success in the market.

\section{Part A - Biases in Investor Behavior}

First, this section will determine and analyze overconfidence, sociability, and the disposition effect with pre-existing investor behavior. This section focuses on the actions of retail investors in contrast to the efforts of institutional traders (such as investment banks). Retail investors are consistently overconfident. There are various forms of overconfidence, such as better-than-average confidence that Barber and Odean (2011) highlight, where an investor believes they are better than the average investor. Next, retail investors access information from standard news outlets and the media, which leads to miscalibration overconfidence. This overconfidence is where investors think they have access to confidential information to make them more successful than others in the market. In the stock market, one's gain is another's loss. It always balances out because investors are competing against each other. Retail investors believe that they will be the winners all the time, but this is not always the case. These retail investors must contend with highfrequency and institutional traders with capacities far surpassing theirs with algorithms to predict the market and 
advanced resources and technology to get advanced real-time information. This enhanced information proves that miscalibration overconfidence is problematic. Due to overconfidence, investors trade too much, which does them a disservice. Hasty decision-making, decreased trading quality, churned portfolios, and thus money losses can result from excessive trading. Furthermore, Barber and Odean (2011) claim that those who "trade the most perform the worst" (Barber and Odean (2011), p. 17). Additionally, levels of overconfidence differ by gender; Barber and Odean indicate men are more prone to overconfidence than women by using data from the large discount brokerage firm with 78,000 investors (LDB dataset) and citing numerous other authors. This difference in overconfidence is further supported by a past Barber and Odean paper (2001), which notes men trade more than women. Barber and Odean note that there is weak evidence claiming that miscalibration leads to increased trading activity from referencing Glaser and Weber (2007), but Barber and Odean note that the surveys used by Glaser and Weber were not large enough to come to this conclusion. There is reasonably strong evidence that proves that the other types of overconfidence, such as the better-than-average overconfidence, lead to increased trading.

Along with overconfidence, the disposition effect subsists as a disruptive force underlying typical investment behavior in which retail investors sell winning stocks but hold on to losing ones. The effect is problematic because, in reality, winning stocks continue to win, and losing stocks continue to lose. Under the disposition effect, retail investors sell their stocks that will improve and hold on to stocks that will worsen: a surefire way to lose profit. Barber and Odean (2011) point to prospect theory as a driver of disposition effect. This is where retail investors enjoy seeing a material gain, so they immediately sell their winners to enjoy profit regardless of what the future entails. Investors do not want to risk experiencing a material loss and see pleasure taken away from them, leading to an endless cycle because of realization utility. One guaranteed win feels like a massive win for a retail investor. They are incentivized to achieve the guaranteed win again to feel pleasure, and emotions intervene with profit. Barber and Odean (2011) highlight another cause for the disposition effect to be that retail investors often look to the past when selling stocks. Stocks can quickly change in value, so the past can often oppose the present based on stock value. Chaudry and Kulkarni (2021) add that the gambler fallacy substantiates disposition effect. Gambler fallacy claims that investors believe that a stock will always revert to its original price. The fallacy means that investors sell a winner because they think it will resort to a loser, which works inversely. The disposition effect differs based on social group because institutional investors undergo the disposition effect but at a lighter degree. They have experience and knowledge to withstand the effect to an extent. Over time, the disposition dwindles because of accustomed experience that teaches one not to fall under the trap anymore. Investors fundamentally overlook innovation that allows a company or product to break past trends, so the disposition effect substantiates flaws in pre-existing investment behavior because pleasure intervenes with profit.

While overconfidence and the disposition effect highlight dangerous behavioral habits, sociability is a crucial cornerstone of investment in the first place. Increased social interaction leads to more investing and stock market participation. Social interaction includes visiting neighbors, having community gatherings, and block parties. Harrison Hong, Jeffrey D. Kubik, and Jeremy C. Stein (2004) study the effect of sociability on investment using data from the Health and Retirement Study from the University of Michigan. They argue that sociability impacts participation through two main factors: information-sharing and enjoyment from talking about the market. First off, when people interact and share information, there is a sense of acknowledgment and familiarity with the market that can lead to increased participation. Next, enjoyment from talking about trading helps bring a sense of kinship to interactions with the market. This enjoyment makes it feel as if stock trading is like a game because investors trade merely for entertainment. If an investor departs the market under information-sharing, the friends and family will still invest because they still have adequate knowledge and information needed. The enjoyment factor is incredibly disruptive. Furthermore, if an investor departs the market, a whole friend or family group of investors will feel emotionally brought down and potentially cease their stock trading.

Thus, the literature has consistently demonstrated that most retail investors have a significant set of biases that affect how they trade; this paper will return to these biases to analyze whether trading apps counter or amplify these biases. 


\section{Part B - Financial Inclusion and Exclusion}

Financial inclusion is defined as the "number of adults having access to banking or financial services" (Mhlanga 2020). In the context of this paper, inclusion and exclusion are regarding access to stock trading and the ability to succeed. This paper will discuss the background of financial inclusion to conceptualize what trading apps are amplifying or diminishing. Financial inclusion has come a long way; society has transitioned to digital financial inclusion. Similar to how financial inclusion did, this era increases access to financial services, but Mhlanga highlights that it also has Information Communication Technology (ICT). ICT includes the internet, increased data, social networking, and many more digitalized features. Modern-day trading apps could be considered an example. They are networking different investors together under one platform, sometimes allowing for social networking with investors and providing information and data.

As referenced in the introduction, with the 4th Industrial Revolution, there has been a vast rise in access to the stock market with increased functionality through cheaper transaction costs and increased and easier account creation. Arguably, an increase in technology has allowed for some financial inclusion. Mhlanga indicates banks, for example, are helping with inclusion through the 4th Industrial Revolution. Digital shopping is more inclusive than inperson because the impoverished are not confined to one payment source. On the other hand, Paolo Giudici (2018) indicates that new fintech developments may be instrumental but, at the same time, risky. Developing safe, regulated technology is necessary because indigent people will often have fewer resources to withstand a risky mishap. Mobile apps now play a role in our lives, and the pandemic led to more trading due to lockdown boredom. Stock trading was a potentially reliable source of income with salary cuts. Mobile-app stock trading with apps like Robinhood then would grow tremendously through increased lockdown trading.

With increased functionality and financial services, people know financial experts can assure them that they have financial stability. TD Ameritrade supports this statement with a study they published. Even if there are risks with technology, people are willing to take that risk for comfort. Furthermore, Suzanee Malhotra (2020) proves that investors' top priority is ease and simple, accessible app usage after conducting a snowball study and then surveying 348 respondents of different genders.

However, the 4th Industrial Revolution also brings risks for financially excluded people and amplifies financial exclusion, which regards people without access to banking and financial services. Fintech increases the likelihood that investors make risky or ill-thought decisions that can cause people to lose money by making trading more accessible and straightforward for everyone. These risky decisions are hazardous for more impoverished people, as losses could be catastrophic for them. Fintech can also exacerbate already existing problems like cybersecurity and fraud. To sum up, with the 4th Industrial Revolution, society is seeing an increase in access to financial services and increased financial inclusion with more access to banking or financial services. For example, digital trading apps have risen in popularity, especially with the pandemic. However, there are risks with recent fintech developments that can amplify exclusion and exacerbate existing problems.

\section{Part C - Designs and Business Models of Trading Apps}

Apps influence behavior and guide an investor to make a trading decision through their designs and business model. The design includes structure, incentives, and emotional triggers. Substantiated by Chaudry and Kulkarni (2021), designs may influence investors to target a jackpot instead of a steady earning. Trading apps use pictures and metaphors and sometimes even lottery-like systems to perpetuate this. Apps have slot machines to show the results immediately, and this furthers an addiction to trading. Furthermore, some apps such as Public allow investors to share information, which leads to overcommitment to specific investments. Other apps deliver alarming news to investors, but the ideal ones try to prevent overreactions and save their typically uninformed investors. Chaudry and Kulkarni claim that different mechanisms influence participants or investors to act in specific ways, like less rationality and more instinct-based investing. More design patterns like the screen's color, the first thing shown when one opens the 
app, and other visible elements influence an investor's heuristic processing. Here, an investor makes decisions based on emotional triggers and influences. Ideally, investors should use systematic processing to make prudent, intelligent decisions.

Even though Robinhood has plentiful criticisms, it does provide accessibility to investors. It allows for oneclick access for quick trading and is a free app with no transaction fees but rather a payment for order flow. It has limited investment portfolio diversity helpers and gives an investor information about future stock performance. However, Chaudry and Kulkarni highlight that some of these criticisms are true. For example, Robinhood attempts to show the investor their risk of investing in stocks, but it does not help inform investors of the risk of investing in a specific stock. This overarching policy may have led to "meme stock" crises because investors were unaware of risk criteria on specific "meme stocks." The app has charted stocks based on daily action and encourages active trading by allowing investors to reinvest immediately. The app has push notifications, which worsen the active trading phenomenon discussed and lead to worried investors. Active trading encouragement can lead to excessive investing, especially from uninformed investors. Lastly, Robinhood provides a free stock at entry, which exemplifies and signals gambling because of the exhilaration of which stock you will receive, how valuable it will be, and initial happiness that can be seen as a reward from joining the app.

On the other hand, Robinhood investors responded well to the pandemic by increasing their holdings instead of panicking. Ivo Welch (2020), an American economist and finance academic, wrote a paper about how the Robinhood crowd is wise. Robinhood investors plugged in money during the pandemic and kept the market alive. However, Welch admits the money plug-in was a rare event, but he highlights that it may not be due to just lucky timing. It could have been because Robinhood investors learned during the pandemic and progressed into developed investors by refraining from panic during an abnormal time. They discovered that their bull-rushing and aggressive behavior led to disruptive market movements throughout the pandemic." Welch wrote his paper in 2020, so his thesis does account for recent trends. A wise Robinhood crowd substantiates that Robinhood investor behavior contrasts with past papers and trends like gambling that this paper has discussed.

To conclude, designs and business models of trading apps influence typical investment behavior and guide traders to make risky decisions. With Robinhood, design features exacerbate and lead to addictive trading, uninformed and risky decision-making, and gambling-like trading. However, Robinhood investors can show intelligence, seen with the pandemic. Robinhood's design and business model could have been the driver of wisdom from pandemic Robinhood investors.

\section{Methods}

This paper uses an interview methodology to answer how trading apps amplify the ability of young people to participate in the stock market. Building on the methodology used by André Renz and Romy Hilbig (2020), who use interviews with 25 Educational Technology (EdTech) companies to analyze technology in the educational sector, this paper uses in-depth semi-structured interviews. Similar to this research, Renz and Hilbig's work study an industry that is affected by artificial intelligence and the 4th industrial revolution, albeit education rather than finance.

This paper uses a convenience sampling approach to select the interviewees. Interviewees were contacted through family and research mentor networks and social media campaigning.

For this paper, ten people were interviewed. Five of them were expert investors, and the other five were casual retail investors. Expert investors included a professor and other MBA graduates from Wharton School of Business, financial experts from private equity firms in the US and Mexico, and a JP Morgan investment banking professional. Retail investors were selected from individuals that are active in stock trading as a hobby, and they typically had other primary unrelated jobs.

Expert investors were asked for their opinion on behavioral biases, certain trading apps, common criticisms of stock trading, and solutions to these criticisms. They were interviewed on a trading platform like Robinhood's role in financial inclusion. Investors were asked about future developments of Robinhood and other trading apps the 
interviewee may be accustomed to and how this would play out. They were asked about different possible solutions to stock trading financial exclusion and how trading apps can play a part. Lastly, retail investors were asked about their journey with trading apps and their pre-existing investor behavior.

The ethical risks are minimum, but interviewees were asked for permission to use names and content. The investors were not asked about any private and sensitive information, and their confidentiality is respected.

Also, like the Renz and Hilbig paper, this paper utilizes a coding process after the interviews to organize notes, highlight vital takeaways, and align segments of the interviews by accentuating correlations and differing opinions. By summarizing sections of interviews, the coding process helped shape the structure of the paper.

\section{Results}

\section{Part A - Overview of Findings}

This section summarizes the findings from the interviews and refers to interview material with permission from interviewees. The interviews highlighted notable common themes. First, modern-day stock trading is becoming like gambling. Next, while expert investors believe there is an unfair resource disparity between expert and retail investors, retail investors accept the disparity to be inevitable. Also, trading apps like Robinhood will shape the stock trading future. Moreover, expert investors believe screening investors for readiness is appropriate. Even more, the interviews substantiated faulty investment habits from retail investors such as overconfidence, lack of attendance for informational webinars, and very high trading app usage. Additionally, retail investors use trading apps based on their usability. Lastly, for Robinhood in particular, retail investors acknowledge that the free stock mechanism can make Robinhood lure investors in and Robinhood has an unsafe history regarding its push notifications.

\section{Part B - Findings from Expert Investors}

Expert investors are professionals in the finance field with deep domain knowledge about stock trading and market dynamics.

\section{Gambling}

Modern-day stock trading on trading apps shows signs of gambling. David Erickson, Professor at The Wharton School of Business, claimed that people are transitioning from gaming to trading on platforms like Robinhood. Another one of the interviewees, Edmundo Recio Prud'Homme, a CFA charter holder from Mexico, agreed, claiming a risk for the trading participants playing with money. However, Prud'Homme contended that the gambling issue is not a massive disturbance for the market in the grand scheme. On the other hand, Charles Howe, a financial services and private equity professional, disagreed with the gambling criticism, claiming that stock traders are merely participants. Finally, Bryan Luce, a private equity financial expert, believed that these incentives and bonuses given by apps that supposedly cause gambling are beneficial as they do end up helping the consumer.

\section{Retail Versus Institutional Investors}

There is a resource disparity between retail and institutional investors, and four expert investors affirmed this observation. Institutional investors have more information and technology. However, this was not a uniform view. Prud'Homme argued that there is still available information. That said, he believes institutional investors naturally have an edge as they are "pros." In contrast, Luce disagreed with this notion. He claims that while retail investors perceive a disadvantage, everyone has the same access to information, and the most excellent firms are still often incorrect. 


\section{Screening Investors for Readiness}

Trading apps should screen investors for their knowledge and readiness. Four of the interviewees mainly affirmed that need. The four who confirmed it believed it could help for caution, but two were wary about the consequences of screening individuals. It is a slippery slope. They believed in free will and access but thought screening would be a beneficial prerequisite beforehand. Luce negated the idea, claiming that society needs fewer regulations. Regardless, he believed that gambling was inevitable through other areas like Las Vegas casinos, not just in trading. However, Erickson believed screening individuals would maintain equal access by merely ensuring investors met certain thresholds. The interviews listed other solutions or necessary influences like international cooperation, limited governmental intervention, technology, and community involvement and awareness.

\section{The Future with Trading Apps}

The stock trading future will look different with these modern-day apps. Erickson claimed that Robinhood is not disruptive in the trading app industry but is a development with new mechanisms like partial stocks (investors can buy parts of a share). At the same time, another interviewee believed there would be an effect on the younger generation with Robinhood. Prud'Homme claimed that these trading apps would be able to grow even without a gambling mindset. On the other hand, Luce believes that technology will benefit these high-frequency traders with the new digital age. They may be able to find patterns in the market with technology. Moisés Junca Acebedo, a CFA holder and investment banking professional, thought that there might be brand erosion with Robinhood in the future. Robinhood as a brand has growing mistrust, and it may prove difficult to get rid of this negative association going forward.

\section{Part C -Findings from Retail Investors}

Retail investors are casual traders who do not have expert, professional knowledge about stock trading and market dynamics and are typically not involved with financial institutions for trading..

\section{Overconfidence}

Overconfidence is very recurrent with casual investors. When asked to rate their investment skills on a scale from one to ten, all five retail investors gave themselves above a five. They reasoned their confidence is based on their knowledge in cryptocurrency, investing experience, keen following of financial news, macro understanding of the financial markets, and basic understanding of investment nuances.

I

\section{nformational Webinars}

Retail investors don't use Informational Webinars conducted by trading apps. Although trading apps do not have to serve as educational platforms and may not be seen that way, the webinars provide helpful investment information. Only one investor believes the webinars are useful and attends them, while the other two investors do not attend the webinars. One claimed that he had time constraints, while another contended that investors who attend the webinars are not relevant enough to influence the market.

\section{Trading App Usage}

Trading frequency in retail investors is high. Three out of four interviews confirmed that modern-day retail investors are using trading apps 15-30 times daily, spending 1-2 hours on the average per day. Only one member that uses TD Ameritrade and Yahoo Finance confirmed his activity as only once a week.

\section{Why Use a Specific App?}

Retail Investors value the usability of trading apps in their choice of platforms. An active cryptocurrency investor preferred Robinhood over other apps because of the fewer clicks in active trading, commission-free trading, and brand 
value. Another investor who uses multiple apps called out that Robinhood is too complex to use in the registration process because it forces the users to reveal financial information and social security number. Though their trading app choices are different, usability is the driving factor in why retail investors choose certain apps over others. Retail investors spanning across multiple apps typically do so to gather distinctive information from different sources.

\section{Retail Versus Institutional Investors}

Retail investors acknowledge the information and resource disparity between them and professionals. Four investors were asked about the information disparity between retail and institutional investors and if it is a fair game or not. Though the responses were mixed, most of them acknowledged that the situation is inevitable. One investor claimed that it is unfair, but individuals can still thrive, while another acknowledged that the divide is unavoidable. One investor claimed that pros are pros, and another interviewee claimed that the apps like Robinhood attempt to bridge the gap by giving access to IPO markets.

\section{Gambling}

Retail investors confirmed stock trading is becoming like gambling. Two investors agreed that it is like gambling through risky decisions and uninformed trading, while another interviewee claimed that the investors are aware of the risk.

\section{Robinhood's Free Stock}

Robinhood's free stock pulls investors into joining the app. Three people interviewed were familiar with Robinhood and were asked about specific details of the app. Robinhood offers a free stock as an incentive to join the app. Retail investors acknowledged that those free stocks mean nothing in the big picture. At the same time, they also called out that the free stock can lure investors towards the platform. Furthermore, one investor substantiates this luring process, pointing out that if an investor refers Robinhood to friends, the investor receives additional free stocks.

\section{Robinhood's Unsafe History}

All three Robinhood investors confirmed unsafe Robinhood practices regarding push notifications when asked various questions about how safe Robinhood is and what improvements can be made. One investor felt that the notifications can be misleading, especially in a bullish market where most news amplify positive views of certain stocks. Also, push notifications are seen at face value instead of what they actually are. Another investor does not notice any safety procedures set in place by the app and believes they could implement basic guidelines like cautioning aggressive trades. Lastly, one interviewee believes that Robinhood is a quality app but can improve by warning the user from dangerous investment behaviors and implementing certain thresholds to reduce the overall risk. He shares that though the app was doing a substandard job earlier, it improved recently after recent controversies such as the GameStop crisis. He believes Robinhood is now giving out an abundance of information through the Weekly Digest.

\section{Analysis}

This section reaches conclusions from the interviews and discusses correlations and differences between retail and expert investors' answers.

All interviewed investors put themselves above the average investor in terms of their skills, which supports Barber and Odean's claim on overconfidence in typical investor behavior. Thoughts like these may cause harmful, addictive, and unreasonable trading. Overconfidence can lead to excessive trading in which one may believe that because they have the most skill, it is justified to trade to accumulate more money. Investors using trading apps like Robinhood are very active in trading with a higher level of confidence. Though Trading Apps provide webinars, investors are either not finding them useful or not allocating enough time to gain that foundational knowledge. Though 
there are known issues with pre-existing investment behavior, trading apps fail to correct them with these informational webinars.

The expert investors claimed that retail versus institutional investors is an unfair game, while retail investors accepted this as inevitable. This finding stands out, confirming that professionals are more worried about information disparity than casual investors, even when institutional investors have better technology and information and are less prone to the disposition effect. On the other hand, casual investors were expected to complain about the situation because it is mainly their loss. These responses signal that expert investors have self-awareness about the issue of information disparity. On the other hand, in support of Barber and Odean's claim on potential overconfidence, retail investors tend to undermine the significance of the information gap, which can lead to dangerous investor behavior. This paper established that there are already harmful investment habits in the status quo with overconfidence. Even more, the webinars that trading apps serve are drawing lackluster attendance. Retail investors may even have a stigma that those who attend are worse than others and may not be relevant in the market. It is clear that apps like Robinhood are addictive, but why does it matter if there will, regardless, be terrible investment habits? At worst, trading apps can only amplify typical investment behavior with their designs and business models, proven by the design section of the literature review. It is also critical to institute balanced investor behavior in our society while cleansing trading apps such as Robinhood.

The interviews substantiate that Robinhood is one example of recent trading apps that encourage addictive and active trading. Users spend 1-2 hours daily with 15-30 app uses on average per day. Robinhood's tactics of giving free stocks for referrals while serving their target to penetrate the market can also lure uninformed investors to join the platform. Trading apps can improve in alerting the users about investment risks involved and can strengthen and implement the screening process.

After the interviews, this research concluded that there are differing takes on these hot-button issues like gambling on trading apps and investment behavior, For example, there was nearly a split on the gambling take with both retail and expert investors, though recent news articles highlight the issue of gambling in stock trading. All these observations show that this is not a one-for-all topic. Everyone has their differing personal opinions on trading apps, investment behavior, and many more. Rather than resorting to the extreme claims that trading apps are the exclusive source of atrocious investment outcomes or that trading apps are blameless, this paper argues for a more nuanced approach. In particular, this paper finds that retail investors are prone to behavioral biases. The trading apps sometimes attempt to counter these issues (e.g., webinars), but they are ineffective. On the other hand, the apps also amplify these biases through their design (e.g., the provision of a free stock or push notifications) and increase the risk of harm.

\section{Conclusion}

Overall, results indicate that Robinhood is one example of an addictive, risky, and dangerous app in the new digital age. Robinhood app usage is distinctly high. Its free stock mechanism, low-click system, push notifications, and more all contribute to this. Additionally, with recent trends, there is at least a possibility of gambling with stock trading, which leads to risky and uninformed decision-making. Any risk of gambling means society should develop a new oriented approach towards our trading situation.

At the same time, our results point out that pre-existing investment biases are dangerous. Rather than solely trading apps, trading apps and behavioral tendencies in combination amplify financial exclusion. Apps feed into behavioral problems. Investors are overly confident about their skills and pay very little attention to informative webinars. This paper made a notable shift in perspective. Recent news articles are swirling around about trading app controversies such as Robinhood with "meme stocks "and Alex Kearns, but what if pre-existing investor behavior is already damaged? Society must address both the behavioral biases exhibited by investors and designs and business models of trading apps to solve aggressive and dangerous trading. Trading apps should improve in educating investors on better behavioral practices. 


\section{Limitations}

While the research for this study was conducted methodically, there are a few limitations to be considered. First, nine of these investors were men, giving a gender bias to the results and potential of reflecting overconfident behavior as mentioned in Part A of the literature review. Also, the sample set may not be large enough to draw statistically conclusive evidence but gives a directionally accurate picture.

\section{Acknowledgments}

This project couldn't have been done without the help of many people. First off, I would like to thank my advisor from Lumiere Education, Dhruva Bhat, for his guidance throughout this project. I would also like to thank many others at Lumiere who helped me, such as Prakriti Sharma, Eric Cheng, and Stephen Turban. I would like to thank my parents who guided me through this project as well. Lastly, this research study was conducted with the help of many interviewees who spent their valuable time sharing their insights including David Erickson, Bryan Luce, Charles Howe, Moisés Junca Acebedo, Edmundo Recio Prud'Homme, Venkat Gajulapalli, Zeel Shah, Shiv Shankar Ganesh.

\section{References}

Ameritrade, T. D. (n.d.). The Tech Effect: How the Digital Age Is Changing Investing. Financial Technologies. https://s2.q4cdn.com/437609071/files/doc_news/research/2018/TDA_FinTech_ebook.pdf.

Avery, J., \& Steenburgh, T. (2018). HubSpot and Motion AI: Chatbot-Enabled CRMJ. HubSpot and Motion AI: Chatbot-Enabled CRM - Case - Faculty \& Research - Harvard Business School. https://www.hbs.edu/faculty/Pages/item.aspx?num=53650.

Barber, B. M., \& Odean, T. (2001). Boys Will Be Boys: Gender, Overconfidence, and Common Stock Investment. The Quarterly Journal of Economics, 116(1), 261-292. https://doi.org/10.1162/003355301556400

Barber, B. M., \& Odean, T. (2011). The Behavior of Individual Investors. SSRN Electronic Journal, 1-52. https://doi.org/10.2139/ssrn.1872211

Barber, B. M., Lee, Y.-T., Liu, Y.-J., \& Odean, T. (2008). Just how much do individual investors lose by trading? Oxford University Press on Behalf of The Society for Financial Studies, 22, 609-632. https://doi.org/10.1093/rfs/hhn046

Chaudhry, S., \& Kulkarni, C. (2021). Design Patterns of Trading Apps and Their Effects on Investing Behaviors. Designing Interactive Systems Conference 2021, 1-18. https://doi.org/10.1145/3461778.3462008

Cohen, L., Malloy, C., \& Powley, W. (2018). Artificial intelligence and the machine learning revolution in finance: Cogent labs and the Google cloud Platform (GCP). Artificial Intelligence and the Machine Learning Revolution in Finance: Cogent Labs and the Google Cloud Platform (GCP) - Case - Faculty \& Research Harvard Business School. https://www.hbs.edu/faculty/Pages/item.aspx?num=53998.

Dokoupil, T., Kaplan, M., Finn, M., McDonald, C., Kamin, J., \& Kaplan, R. (2021, February 8). Alex Kearns died thinking he owed hundreds of thousands for stock market losses on robinhood. his parents have sued over his suicide. CBS News. https://www.cbsnews.com/news/alex-kearns-robinhood-trader-suicide-wrongful-deathsuit/.

Fink, C. (2021). Why millennials gravitate to new brands in online investing. Provoke Insights. https://provokeinsights.com/wp-content/uploads/2021/04/JBS_9_4_JBS0002_Fink.pdf.

Gao, X., \& Lin, T.-C. (2014). Do Individual Investors Treat Trading as a Fun and Exciting Gambling Activity? Evidence from Repeated Natural Experiments. The Review of Financial Studies, 28(7), 2128-2166. https://doi.org/10.1093/rfs/hhu075 
Giudici, P. (2018). Fintech risk management: A Research challenge for artificial intelligence in finance. Frontiers in Artificial Intelligence, 1, 1-6. https://doi.org/10.3389/frai.2018.00001

Glaser, M., \& Weber, M. (2007). Overconfidence and Trading Volume. SSRN Electronic Journal, 1-56. https://doi.org/10.2139/ssrn.626761

Griffith, E. (2021, July 1). Robinhood reveals rising revenue and a $\$ 1.4$ billion loss. The New York Times. https:/www.nytimes.com/2021/07/01/technology/robinhood-ipo-financials.html.

Hayes, A. (n.d.). Retail investor. Investopedia. https://www.investopedia.com/terms/r/retailinvestor.asp.

Hong, H., Kubik, J. D., \& Stein, J. C. (2004). Social interaction and Stock-Market Participation. The Journal of Finance, 59(1), 137-163. https://doi.org/10.1111/j.1540-6261.2004.00629.x

Horstmeyer, D., \& Mayer, V. (2021, August 9). Meme Stocks and Systematic Risk. CFA Institute Enterprising Investor. https://blogs.cfainstitute.org/investor/2021/08/09/meme-stocks-and-systematic-risk/.

Kannadhasan, M. (2015). Retail investors' financial risk tolerance and their risk-taking behaviour: The role of demographics as differentiating and classifying factors. IIMB Management Review, 27(3), 175-184. https://doi.org/10.1016/j.iimb.2015.06.004

Lee, I., \& Shin, Y. J. (2018). Fintech: Ecosystem, business models, investment decisions, and challenges. Business Horizons, 61(1), 35-46. https://doi.org/10.1016/j.bushor.2017.09.003

Lewis, M., \& Bishop, P. J. (2015, March 12). Michael Lewis reflects on his book Flash boys, a year after it Shook Wall Street to its core. Vanity Fair/HIVE. https:/www.vanityfair.com/news/2015/03/michael-lewis-flashboys-one-year-later.

Maggiulli, N. M. (2020, September 1). No, Robinhood traders aren't affecting the stock market. Of Dollars And Data. https://ofdollarsanddata.com/robinhood-trader/.

Malhotra, S. (2020). Study of features of mobile trading apps: A silver lining of pandemic. Journal of Global Information and Business Strategy, 12(1), 75-80. https://doi.org/10.5958/2582-6115.2020.00009.0

Mhlanga, D. (2020). Industry 4.0 in finance: The impact of artificial intelligence (ai) on digital financial inclusion. International Journal of Financial Studies, 8(3), 45. https://doi.org/10.3390/ijfs8030045

Morrissey, J. (2017, February 18). With no frills and No Commissions, Robinhood app takes on Big brokerages. The New York Times. https://www.nytimes.com/2017/02/18/business/robinhood-stock-trading-app.html.

Moss, A., Naughton, J. P., \& Wang, C. (2020). The irrelevance of ESG disclosure to Retail Investors: Evidence from Robinhood. SSRN Electronic Journal, 1-36. https://doi.org/10.2139/ssrn.3604847

Popper, N. (2020, July 8). Robinhood has Lured Young Traders, sometimes with devastating results. The New York Times. https:/www.nytimes.com/2020/07/08/technology/robinhood-risky-trading.html.

Renz, A., \& Hilbig, R. (2020). Prerequisites for artificial intelligence in further education: Identification of drivers, barriers, and business models of educational technology companies. International Journal of Educational Technology in Higher Education, 17(1), 1-21. https://doi.org/10.1186/s41239-020-00193-3

Schwab, K. (2017). The fourth industrial revolution. Currency.

Steib, B. (2021). 'The Robinhood Effect' - Digital technology in global financial markets and its effects on investor decision making. Digital Commons @ Colby. https://digitalcommons.colby.edu/cgi/viewcontent.cgi?article=2338\&context=honorstheses.

Welch, I. (2020). The Wisdom of the Robinhood Crowd, 2-51. https://doi.org/10.3386/w27866

YouTube. (2019). What is Artificial Intelligence? Crash Course Ai \#1. YouTube. https://www.youtube.com/watch?v=a0_lo_GDcFw.

Zuckerman, E. W. (2004). Structural Incoherence and Stock Market Activity. American Sociological Association, 69(3), 405-432. https://doi.org/10.1177/000312240406900305 
